\title{
ENVIRONMENTALISTS, RESEARCHERS AND BLOGGERS IN THE CAP-POLICY NETWORKS
}

\begin{abstract}
The article aims to examine the role of non-farm actors and environmental interest groups in the Common Agricultural Policy (CAP) of the European Union (EU). It uses policy networks as an analytical tool to understand the structure, dynamics and outcomes of the EU's agricultural decision-making processes. Both locations of actors in the CAP policy structures and interaction modes between actors are examined. Also, the role of networks in shaping the CAP's reform decisions is assessed. The article shows that non-farm actors, and specifically environmentalists, researchers and other agents interested in major CAP reforms, have limited influence on final policy outcomes. At the same time though it has been found that non-farm actors play an increasingly important role in framing the CAP policy debate. They form active and vocal issue networks that impinge upon initial stages of the agenda setting phase in the policy cycle process. Also, the EU institutions become more and more dependent on non-farm actors' expertise when it comes to policy evaluation. Although the pro-reform approach of these actors is clearly noticeable, it is still too small to bring more than incremental changes within the policy.
\end{abstract}

\section{Key words}

policy networks, common agricultural policy, reforms

\section{Introduction}

Decision-making processes in the area of the Common Agricultural Policy (CAP) of the European Union (EU) have long attracted considerable attention of researchers dealing with public policy analysis. The CAP is one of the oldest and at the same time the most complex policies of the EU absorbing a significant part of the common budget. A large commitment of public funds to the benefit 